\title{
Tissue scurvy misdiagnosed as murder
}

\author{
Michael D. Innis \\ Retired HaematologistPrincess Alexandra Hospital Brisbane Australia
}

Email address:

micinnis@bigpond.com

To cite this article:

Michael D. Innis. Tissue Scurvy Misdiagnosed as Murder. Clinical Medicine Research. Vol. 3, No. 3, 2014, pp.65-67.

doi: 10.11648/j.cmr.20140303.13

\begin{abstract}
Background: Mr Darryl Elliot was convicted for the murder of Amelia Bowmar on the evidence of doctors who alleged Amelia was a victim of the Shaken Baby Syndrome because ofthe presence of a subdural haematoma, swelling of the brain with ischaemic changes and haemorrhagic contusions in the cortex of the right and left superior frontal gyri of the brain. The brain and spinal cord showed evidence of old and recent injury which the doctors attributed to "Nonaccidental Injury". Method: To prove that the allegation of murder was false the results of the blood tests were analyzed. Result:It is shown that the child had evidence of abnormal coagulation of blood, liver dysfunction and hypoinsulinaemia following mandated MMR vaccine administered a few days prior to the onset of symptoms. Conclusion:The Laboratory results prove the presence of vaccine induced Tissue Scurvy which would account for all the lesions found on the child.
\end{abstract}

Keywords:Tissue Scurvy, Shaken Baby Syndrome, Non-Accidental Injury, Murder

\section{Introduction}

Tissue Scurvy, resulting from an inability of Vitamin C to enter cells and promote cellular function [1], explains the haemorrhages and fractures found on children alleged to have been victims of the Shaken Baby Syndrome, Nonaccidental Injury, Abusive Head Trauma and Inflicted Brain Injury. It also explains the axonal damage in the spinal cord, demonstrated with $\beta$ APP, which is associated with these diagnoses. Axonal cells control the respiratory centre and, like any other cell, perish without Vitamin $\mathrm{C}$ and the result is the Hypoxic Ischaemic Encephalopathy seen in this condition. The violent hyper-extension and hyper-flexion of the head and neck which some doctors believe cause the lesion, has no scientific basis and is untrue- "only if what they affirm agrees with observed facts" is true said Aristotle [2]. Who has observed the violence they assert cause the axonal lesions?

Doctors making the assertion have no answer.

Tissue Scurvy, on the other hand provides a scientific explanation for the Axonal injury.

In 1894 Townsend [3] published his findings of an infant who, shortly after birth spontaneously developed bilateral acute subdural haematomas. The disease was called Haemorrhagic Disease of the Newborn and the cause was later attributed to Vitamin $\mathrm{K}$ deficiency and the routine administration of Intramuscular Vitamin $\mathrm{K}$ at birth became standard practice to counteract the problem.
The Scottish physician Douglas [4] brought the attention of the profession to "the seasonalities of fractured neck of femur and haemorrhagic disease of the newborn" in 1993, thus providing evidence of the association of fractures and haemorrhages in children resulting from a deficiency of Vitamin K.

This association of fractures and haemorrhages in children with vitamin $\mathrm{K}$ deficiency is explained by the fact that Vitamin $\mathrm{K}$ is essential for the carboxylation of both Osteocalcin (bone forming hormone) and Intrinsic Clotting Factors (II, VII, IX and X). Without Vitamin K carboxylation cannot occur and both bone formation and blood clotting are impaired [5].

Carboxylation occurs in the Liver by the action of the enzyme $\gamma$-glutamyl carboxylase which requires Vitamin K as a cofactor. With impaired Liver function, as occurs in new-born children with Alpha1-antitrypsin deficiency, Biliary atresia, Celiac disease, Cystic fibrosis and Hepatitis or by anticonvulsant drugs and some antibiotics consumed by the mother during her pregnancy, both fractures and haemorrhage are likely. In assessing the cause of haemorrhage and fractures in children one must investigate the adequacy of the Liver function before alleging child abuse [6].

Also essential for the control of haemostasis and the prevention of fractures is the integrity of the blood vessels and the integrity of the skeletal tissues. Both are dependent on the production of collagen which lines the blood vessels and 
forms the ground substance of bone. Collagen is formed within certain cells, fibroblasts, osteoblasts and chondroblasts, by the hydroxylation of the amino acids proline and lysine by Vitamin C. It is the paucity and malfunction of collagen, resulting from an absence of intracellular Vitamin $\mathrm{C}$, which is responsible for both the vascular and skeletal lesions seen in both Sea Farer Scurvy (nutritional deficiency of Vitamin C) and Tissue Scurvy(insulin deficiency inhibiting the entry of Vitamin $\mathrm{C}$ into the cells).

When Vitamin $\mathrm{C}$ is deficient or unable to enter the cell as in Tissue Scurvy, hydroxylation of proline and lysine is impaired, and the end result is poor wound healing haemorrhages and fractures - as was pointed out by Dr Archie Kalokerinos who recalls, "during one trial, the prosecution stated that infantile scurvy was no longer seen. I replied, yes it is. But it is no longer called 'scurvy' it is called 'the Shaken Baby Syndrome'[7].

The Shaken Baby Syndrome also known as Nonaccidental Injury, Inflicted Brain Trauma, Abusive Head Trauma, is the name given to signs and symptoms involving retinal and subdural haemorrhages with encephalopathy in a child. The cause of the lesions is attributed to violent shaking of the infant by the last individual to have had contact prior to the onset of symptoms.

The diagnosis was originally suggested by a neurosurgeon; Dr A N Guthkelch., in a two-page article published in the British Medical Journal entitled "Infantile Subdural Hematoma and Its Relationship to Whiplash Injuries [8].

Unsurprisingly, he could offer no other explanation for the lesions he observed and his advice has been followed by some in the Medical Profession who have offered a variety of explanations for the manner in which these lesions are inflicted from bashing the infants head against a hard object, forcibly compressing the chest to fracture the ribs and injuring the limbs to fracture the long bones [9].

Darryl Elliot was convicted and imprisoned for murder of Amelia Bowmar on medical evidence. His mother sent me the information used in this report.

\section{Case Report}

Darryl Elliot, of Stapleford, was jailed for a minimum of 15 years at Nottingham Crown Court having been found guilty of allegedly murdering Amelia Bowmar by violently shaking the 14-month-old causing devastating brain injuries.

Amelia Bowmar was born on the $9^{\text {th }}$ May 2011 and she received her mandated vaccines on $23^{\text {rd }}$ May 2012. On the $2^{\text {nd }}$ June 2012, nine days after being vaccinated, she developed a" lump on her head and a bite mark on limb". The possibility of the "lump on her head" being a haematoma and the "bite mark" a bruise following a vaccine reaction was not considered.

On July $28^{\text {th }} 2012$ she was at home in the care of $\mathrm{Mr}$ Darryl Elliot when she suddenly became unconscious, started gasping for air and went floppy. He immediately dialed the Emergency Service and Amelia was taken to the Grimsby Hospital where emergency treatment was given. No bruising was observed and a CT scan of the head was described as normal.

She was transferred to Sheffield Children's Hospital where a further CT scan was reported as showing extensive bilateral loss of grey/white matter differentiation with relative preservation of parafalcine cortex, basal ganglia and cerebellum. The difference between the two CT scans was thought to be due to the development of diffuse cerebral oedema/ischemia in the interval between the scans.

Ophthalmoscopy revealed extensive retinal haemorrhages and a diagnosis of Non-accidental Injury was made. Amelia suffered prolonged seizures and was declared brain dead on $31^{\text {st }}$ July 2012 .

A post-mortem examination was conducted and the report showed:

Central Nervous System. Bruising was noticed on the left parietal area of the scalp approximately $3.5 \times 2 \mathrm{~cm}$. Whether it was the remains of the "lump on the head" which had been reported earlier was not discussed. The skull bones were intact. The brain was markedly swollen with a thin film of subdural haemorrhage present over both hemispheres. Dr Al-Sarraj carried out a microscopic examination and concluded the brain and spinal cord showed evidence of old and recent injury and concluded the injuries were consistent with Non-accidental Injury. Axonal damage of the cortico-spinal tract was demonstrated with $\beta$ APP staining and thought to be diagnostic of hyper-extension and hyper-flexion of the head and neck during violent shaking proving murder.

Concluding his post-mortem report Dr S J Hamilton, Deputy Chief Forensic Pathologist East Midlands, said " Ocular Pathology showed severe and extensive bilateral retinal haemorrhages, haemorrhagic macular folds and optic nerve sheath bleeding which is strongly associated with trauma, either non-accidental injury or severe accidental injury". He also said "there is no evidence that Amelia had any form of clotting abnormality", which is untrue as shown by an INR of 1.3 and an APTT of 39.6 both of which are abnormal and clearly indicate a clotting abnormality.

In sentencing the accused the Judge said, "It makes harrowing reading; it moved me almost to tears; the sadness and anguish which you have caused. Only you know exactly what went on inside that house on 28th July last year," but the prisoners version of events was ignored. Instead the Judge believed the doctors and the fate of Darryl Elliot was sealed!

He believed Dr P.H.T. Cartlidge Specialist field: Paediatrics who concluded. "In my opinion the recent subdural bleeding, the hypoxic-ischaemic brain injury and the retinal haemorrhages were caused non-accidentally immediately before Amelia collapsed shortly before 16.30 hours on the 28July 2012. I find that the injuries were caused primarily by shaking, although I cannot exclude an impact 
with a yielding object, or a minor impact with an unyielding object. The only revealed event to explain the histological findings of earlier head and retinal injuries was the head injury sustained within a few days of 1 June 2012".

A "revealed event to explain the histological findings" which he and the other experts ignored was recorded in the evidence of Dr J Jayamohan who said "Initial blood clotting tests show some raised clotting times with an INR of 1.3, an APTT of 39.6 an APTT ratio of 1.3 also. This would require re-testing to see if there is an abnormality of the blood clotting, or if this is a reaction to extreme stress also. The ratios are similar to levels $I$ have seen in babies after trauma previously, and as a neurosurgeon, I would not count them as very aberrant. A haematologist or paediatrician may be better placed to comment overall however."

As a retired Haematologist, and a former Coroners Pathologist in the West Riding of Yorkshire, I can confirm that this isindeed the crucial evidence of a coagulopathy which explains all the lesions found in Amelia but the evidence was ignored by the doctors alleging murder.

Their preoccupation with the Shaken Baby Syndrome hypothesis also ignored the elevation of the level of Glucose in the blood and the presence of Glucose in the Urine of Amelia. Both these features are manifestations of an autoimmune response to antigenic stimulationwhich destroyed the cells in the Liver responsible for the carboxylation of the clotting factors and osteocalcin. In this case it was the vaccines given to Amelia a few days prior to her falling ill which initiated the autoimmune process.

One has to be wary that glycosuria and diabetes mellitus do not become evidence of Shaken Baby Syndrome.

The USA, England, Canada and Australia are the victims of a medical profession unable to comprehend what Dr Archie Kalokerinos and Dr Mark Struthers tried to instil into their psyche - Tissue Scurvy is the Diagnosis not Shaken Baby Syndrome.

Unless there is a sea change in which younger doctors are taught the truth the prospect looks bleak for Darryl Elliot and others caught up in this malicious diagnosis.

All those incarcerated on a doctor's evidence of nonaccidental injury should be released and compensated.

\section{Acknowledgements}

I wish to acknowledge the help I received from Elizabeth Peel, the mother of Darryl Elliot and from Darryl Elliot who provided me, from his prison cell, with some of the information. My wife assisted me with the preparation of the manuscript.

\section{References}

[1] Michael D Innis, Autoimmune Tissue Scurvy Misdiagnosed as Child Abuse, Clinical Medicine Research. Vol. 2, No. 6, 2013, pp. 154-157. doi: 10.11648/j.cmr.20130206.17.

[2] Great Books Of The Western World. An Index of The Great Ideas. Britanica Mortimer Adler Editor in Chief. pp 727 736.

[3] TownsendCW. Arch. Pediat.1894;11:558.

[4] Douglas AS. Seasonality of hip fracture and haemorrhagic disease of the new-born. Scott Med J. 1993 Apr;38(2):3740.

[5] Morris DP, Stevens RD, Wright DJ, Stafford DW (1995). "Processive post-translational modification. Vitamin Kdependent carboxylation of a peptide substrate". J. Biol. Chem. 270 (51): 30491-8.

[6] Innis M D Malnutrition, Liver Dysfunction, Subdural and Retinal Haemorrhages and Encephalopathy in Children Resulting from a Deficiency or Abnormality of Vitamins C, $\mathrm{D}$ and $\mathrm{K}$.

[7] Kalokerinos A. Every Second Child. 1981 pp 3-165 Thomas Nelson (Australia)

[8] Guthkelch A N Infantile Subdural Haematoma and its Relationship to Whiplash Injuries Br Med J. May 22, 1971; 2(5759): 430-431.

[9] Maguire S, Pickard N, Farewell D, Mann M, et al; Which clinical features distinguish inflicted from non-inflicted brain injury? A systematic review. Arch Dis Child 2009, 94:880-887. 